Available online at GSC Online Press Directory

GSC Biological and Pharmaceutical Sciences

e-ISSN: 2581-3250, CODEN (USA): GBPSC2

Journal homepage: https://www.gsconlinepress.com/journals/gscbps

(RESEARCH ARTICLE)

\title{
Formulation and evaluation of lovastatin oral disintegration thin films
}

\author{
Pagilla Pragathi *, Vishnu P, Konde Abbulu \\ Department of Pharmaceutics, CMR College of Pharmacy, Kandlakoya (V), Medchal Road, Hyderabad, India.
}

Publication history: Received on 12 October 2017; revised on 02 May 2018; accepted on 05 May 2018

https://doi.org/10.30574/gscbps.2018.3.2.0061

\begin{abstract}
Lovastatin is a statin drug used to prevent and treat coronary heart disease and to treat high cholesterol. In the present study, oral disintegrating thin films (ODTs) of lovastatin were designed with a view to enhance patient compliance by solvent casting method. In the solvent casting method, Croscarmellose sodium (CCS) (2, 4 and $6 \%$ w/w), Crospovidone (10 and 15\% w/w) as superdisintegrants were used in different concentrations with Gelatin, Poly vinyl alcohol (PVA) as a film forming base for the formulation of oral disintegrating thin films of lovastatin. The prepared formulations of films were evaluated for film thickness measurement, folding endurance study, in-vitro disintegration time, in-vitro drug release pattern and drug content. FTIR spectroscopy used to study drug-polymers interaction. Among all formulations, the formulation (F8) prepared by 4\% crospovidone show enhanced drug release (99.27\%) and it showed good stability for period of three months. Conclusively, the present study documents the development of a commercially viable formula lovastatin ODTs with rapidity in reducing heart problems.
\end{abstract}

Keywords: Croscarmellose sodium; Crospovidone; Lovastatin; Oral disintegrating thin films

\section{Introduction}

Among the different routes of administration, the oral route of administration continues to be most preferred route due to various advantages including ease of administration, avoidance of pain, versatility and most importantly patient compliance [1]. Many patients especially geriatric and paediatric have difficulty to swallow the tablets and hard gelatin capsules. Fast dissolving drug delivery systems (FDDDS) were developed as an alternative to tablet, capsule and syrups [2]. Oral fast dissolving film is relatively a new dosage form in which thin film is prepared using hydrophilic polymers, which rapidly disintegrate or dissolves on tongue or in the buccal cavity [3].

Oral administration is the most popular route due to ease of ingestion, pain avoidance, versatility (to accommodate various types of drug candidates), and most importantly, patient compliance [1]. But the most evident drawback of oral dosage forms like tablets and capsules are difficulty in swallowing, leading to patient's incompliance particularly in case of pediatric and geriatric, bedridden, nauseous patients [4]. Fast dissolving drug delivery systems (FDDDS) were developed as an alternative to tablet, capsule and syrups. These systems consist of the solid dosage forms that disintegrate and dissolve quickly in the oral cavity without the administration of water. Rapid-dissolving oral thin film is a solid dosage form, which disintegrate or dissolve within 1 min when placed in the mouth without drinking of water or chewing [5]. After disintegrating in mouth, enhanced the clinical effect of drug through pre-gastric absorption from mouth pharynx and oesophagus as the saliva passes down into the stomach. In such cases, bioavailability of drug is significantly greater than those observed from conventional tablet dosage form [1].

Lovastatin, a specific and potent competitive inhibitor of 3-hydroxy3-methyl glutaryl coenzyme A (HMG-CoA) is a powerful serum cholesterol-lowering drug in humans and other species. It inhibits HMG-CoA reductase (E.C 1.1.1.34),

\footnotetext{
${ }^{*}$ Corresponding author

E-mail address: pragathireddypagilla@gmail.com
}

Copyright (C) 2018 Author(s) retain the copyright of this article. This article is published under the terms of the Creative Commons Attribution Liscense 4.0. 
Pagilla et al. / GSC Biological and Pharmaceutical Sciences 2018, 03(02), 035-042

the first committed enzyme of cholesterol biosynthesis [6-7]. Lovastatin is a statin drug used to prevent and treat coronary heart disease, and to treat high cholesterol [8]. Therefore, the objective of present work was to develop oral disintegration thin films of lovastatin and evaluate for its different physical properties and drug release study.

\section{Material and methods}

\subsection{Chemicals}

Lovastatin (Matrix Pvt. Ltd. Hyderabad), Gelatin, PEG 400, Citric acid, Sucrose (S. D. Fine Chemical Limited, Mumbai), HPMC (Himedia Lab. Pvt. Ltd., Mumbai), Crospovidone, Croscarmellose sodium (Signet Chemical Corporation Pvt. Ltd., Mumbai), Trusil mixed flavor RSV (International flavors of fragrance, India Ltd ).

\subsection{Instruments used}

Electronic balance obtained from (Citizen CTG - 302), Digital pH meter (Hanna Instruments, Italy), Hot air oven (Servewell Instruments, Bangalore), Tablet dissolution tester (USPXXIV) (Electro Lab), UV spectrophotometer (Shimadzu), FTIR spectrophotometer (Shimadzu), Humidity chamber (Thermo Lab.), Differential scanning calorimetry (METTLER), Scanning electron microscopy (QUANTA-200 FEI, Netherland).

\subsection{Drug-excipient compatibility study}

FTIR spectra of pure drugs, polymers used, and blends were recorded on KBR disk method using FTIR-8400S Spectrophotometer with IR solution software (Shimadzu, Japan) to confirm the compatibility between drug and excipients. Sample powder was thoroughly mixed by triturating with potassium bromide in a glass mortar with pestle and compressed into disks in a hydraulic press (Techno search Instruments, India). FTIR spectra of all the samples were recorded over a spectral region from 4700 to $400 \mathrm{~cm}^{-1}$ using 20 scans with $4 \mathrm{~cm}^{-1}$ resolution.

\subsection{Formulation of oral disintegrating thin films (ODT) of lovastatin}

The oral disintegrating thin films of lovastatin were prepared by solvent casting method [9-10] employing mercury as substrate. The ODT films were prepared using polymers like gelatin, PVA. Propylene glycol (PEG) is used as plasticizer. The calculated amount of polymer was dispersed in three forth volume of with continuous stirring using magnetic stirrer and the final volume was adjusted with distilled water. The calculated amount of lovastatin was incorporated in the polymeric solutions after levigation with required volume of PEG. The solution was casted on to mercury substrate then kept in hot air oven at $40{ }^{\circ} \mathrm{C}$. The films were punched in to size $2 \mathrm{~cm}$ diameter containing $4 \mathrm{mg}$ of lovastatin. For the trial and error method different concentrations of film forming polymers were used like gelatin and PVA. It has been found that $4.5 \%$ of gelatin, 3.5\% of PVA shows better films. Therefore this concentration of gelatin and PVA used for preparation of ODT film of lovastatin. In addition to this CCS and crospovidone are also added in the thin film in different concentration which gives different type of formulation of lovastatin as shown in table 1 . With the same procedure the films of 4.5\% gelatin, 3.5\% PVA were prepared without the super disintegrating agents named as Fg and Fp respectively.

Table 1 Formulation details of lovastatin oral disintegrating thin films

\begin{tabular}{|c|c|c|c|c|c|c|c|c|c|}
\hline Formulation & $\begin{array}{l}\text { Lovastatin } \\
\text { (mg) }\end{array}$ & $\begin{array}{l}\text { Gelatin } \\
\text { (mg) }\end{array}$ & $\begin{array}{l}\text { PVA } \\
\text { (mg) }\end{array}$ & $\begin{array}{c}\text { CCS } \\
\text { (mg) }\end{array}$ & $\begin{array}{c}\text { Crospovidone } \\
\text { (mg) }\end{array}$ & $\begin{array}{l}\text { Sucrose } \\
\text { (mg) }\end{array}$ & $\begin{array}{c}\text { Citric } \\
\text { acid } \\
\text { (mg) }\end{array}$ & $\begin{array}{c}\text { Trusil } \\
\text { flavor } \\
\text { (mg) }\end{array}$ & $\begin{array}{l}\text { PEG } \\
\text { (mg) }\end{array}$ \\
\hline F g & 50 & 4.5 & -- & -- & -- & 4 & 4 & 8 & 30 \\
\hline $\mathrm{F} 1$ & 50 & 4.5 & -- & 2 & -- & 4 & 4 & 8 & 30 \\
\hline F2 & 50 & 4.5 & -- & 4 & -- & 4 & 4 & 8 & 30 \\
\hline F3 & 50 & 4.5 & -- & 6 & -- & 4 & 4 & 8 & 30 \\
\hline $\mathrm{F} 4$ & 50 & 4.5 & -- & -- & 10 & 4 & 4 & 8 & 30 \\
\hline F5 & 50 & 4.5 & -- & -- & 15 & 4 & 4 & 8 & 30 \\
\hline $\mathrm{Fp}$ & 50 & -- & 3.5 & -- & -- & 4 & 4 & 8 & 30 \\
\hline F6 & 50 & -- & 3.5 & -- & 10 & 4 & 4 & 8 & 30 \\
\hline F7 & 50 & -- & 3.5 & 2 & -- & 4 & 4 & 8 & 30 \\
\hline F8 & 50 & & 3.5 & 4 & -- & 4 & 4 & 8 & 30 \\
\hline F9 & 50 & -- & 3.5 & 6 & -- & 4 & 4 & 8 & 30 \\
\hline F10 & 50 & -- & 3.5 & -- & 15 & 4 & 4 & 8 & 30 \\
\hline
\end{tabular}


Pagilla et al. / GSC Biological and Pharmaceutical Sciences 2018, 03(02), 035-042

\subsection{Evaluation of lovastatin ODT}

Lovastatin ODTs were evaluated for weight uniformity, thickness uniformity, folding endurance, surface $\mathrm{pH}$, in vitro disintegration time, and drug content uniformity [9-10].

\subsubsection{Weight uniformity}

Three films of the size $2 \mathrm{~cm}$ diameter were weighed individually using digital balance and the average weights were calculated.

\subsubsection{Thickness}

Thickness of the films was measured using screw gauge with a least count of $0.01 \mathrm{~mm}$ at different spots of the films. The thickness was measured at three different spots of the films and average was taken.

\subsubsection{Folding endurance}

The flexibility of films can be measured quantitatively in terms of what is known as folding endurance. Folding endurance of the films was determined by repeatedly folding a small strip of the films (approximately $2 \times 2 \mathrm{~cm}$ ) at the same place till it broke. The number of times films could be folded at the same place, without breaking gives the value of folding endurance [11].

\subsubsection{Surface $\mathrm{pH}$}

Surface $\mathrm{pH}$ was determined by the films were allowed in contact with $1 \mathrm{ml}$ of distilled water. The surface $\mathrm{pH}$ was noted by bringing a combined glass electrode or $\mathrm{pH}$ paper near the surface of films and allowing equilibrate for $1 \mathrm{~min}$.

\subsubsection{In vitro disintegration time}

Disintegration test was performed in the USP disintegration time testing apparatus. The $0.1 \mathrm{~N} \mathrm{HCl}$ solution used as medium. The films were places in the tubes of the container and disintegration time was recorded.

\subsubsection{Drug content uniformity}

The films were tested for drug content uniformity by UV spectrophotometric method. Films of $2 \mathrm{~cm}$ diameter were cut from three different places from the casted films. Each patch was placed in $100 \mathrm{ml}$ volumetric flask and dissolved in $0.1 \mathrm{~N} \mathrm{HCl}$ solution and $0.2 \mathrm{ml}$ is taken and diluted with water up to $10 \mathrm{ml}$. The absorbance of the solution was measured at $238 \mathrm{~nm}$ using UV/visible spectrophotometer (Shimadzu UV-1700). The percentage drug content was determined using the standard graph and the same procedure was repeated for three films.

\subsection{In-vitro dissolution Study [12]}

In vitro dissolution of lovastatin oral disintegrating thin films was studied in USP XXIV dissolution test apparatus $900 \mathrm{ml} 0.1 \mathrm{~N} \mathrm{HCl}$ solution was used as dissolution medium. The stirrer was adjusted to rotate at $50 \mathrm{rpm}$. The temperature of dissolution medium was maintained at $37 \pm 0.5{ }^{\circ} \mathrm{C}$ throughout the experiment. One film was used in each test. Samples of dissolution medium $(5 \mathrm{ml})$ were withdrawn by means of syringe fitted with pre-filter at known intervals of time and analyzed for drug release by measuring the absorbance at $238 \mathrm{~nm}$. The volume withdrawn at each time interval was replaced with fresh quantity of dissolution medium. Cumulative percent lovastatin released was calculated and plotted against time.

\subsection{Stability studies}

Stability studies were carried out at $40{ }^{\circ} \mathrm{C} / 75 \pm 0.005 \% \mathrm{RH}$ for the selected formulation for the period of 3 months for their physical appearance, drug content and in-vitro dispersion time.

\section{Results and discussion}

\subsection{Drug-excipient compatibility study}

Compatibility studies were performed using FT-IR spectrophotometer. The IR spectrum of pure drug and physical mixture of drug and polymer were studied by making a KBR disc. The characteristic absorption peaks of Lovastatin were obtained at different wave numbers in different samples. 
The spectra for pure drug and optimized formulation are shown below. The peaks obtained in the spectra of each formulation correlates with the peaks of drug spectrum. This indicates that the drug is compatible with the formulation components [13].

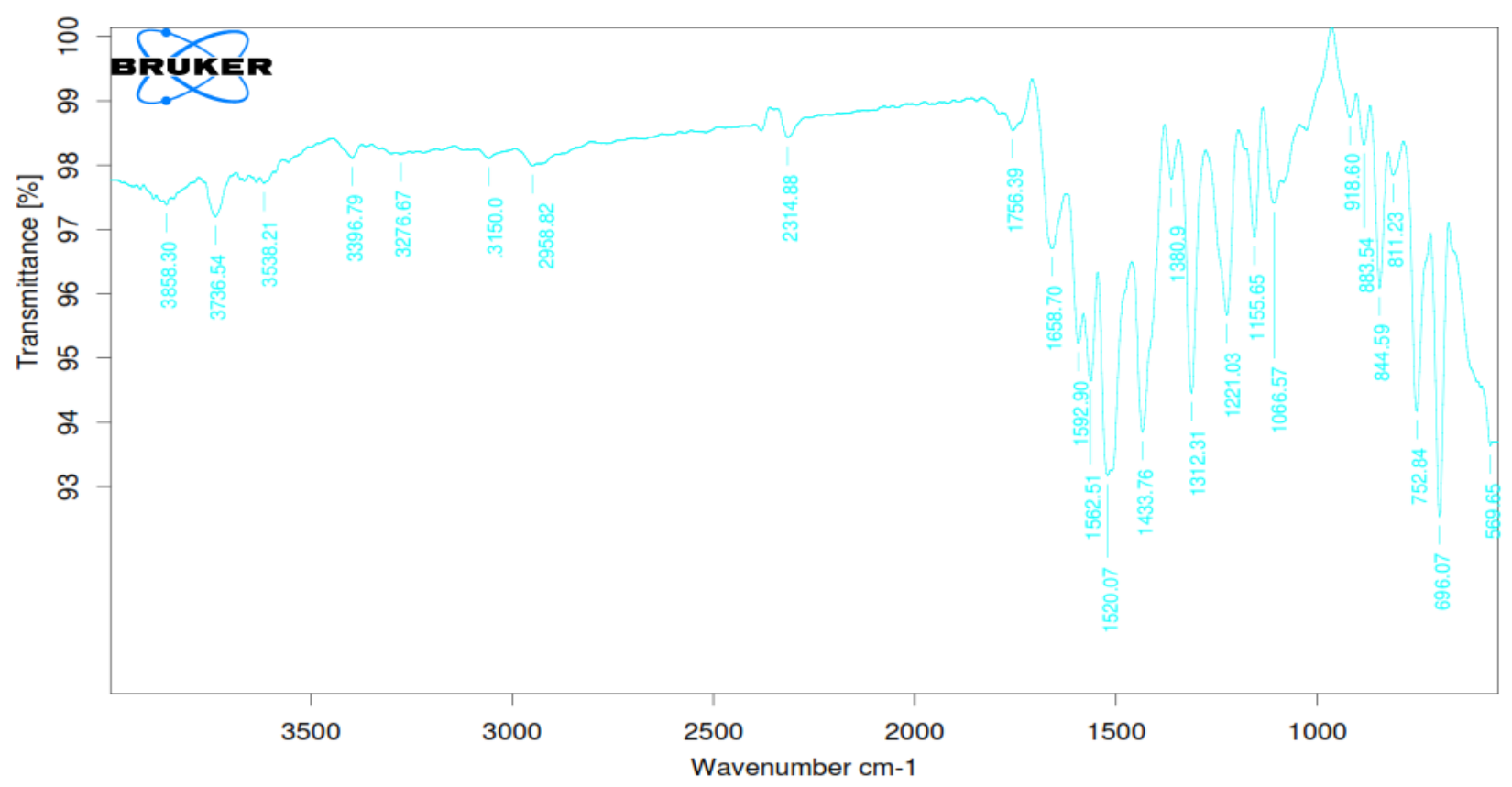

Figure 1 FTIR spectrum of pure drug lovastatin

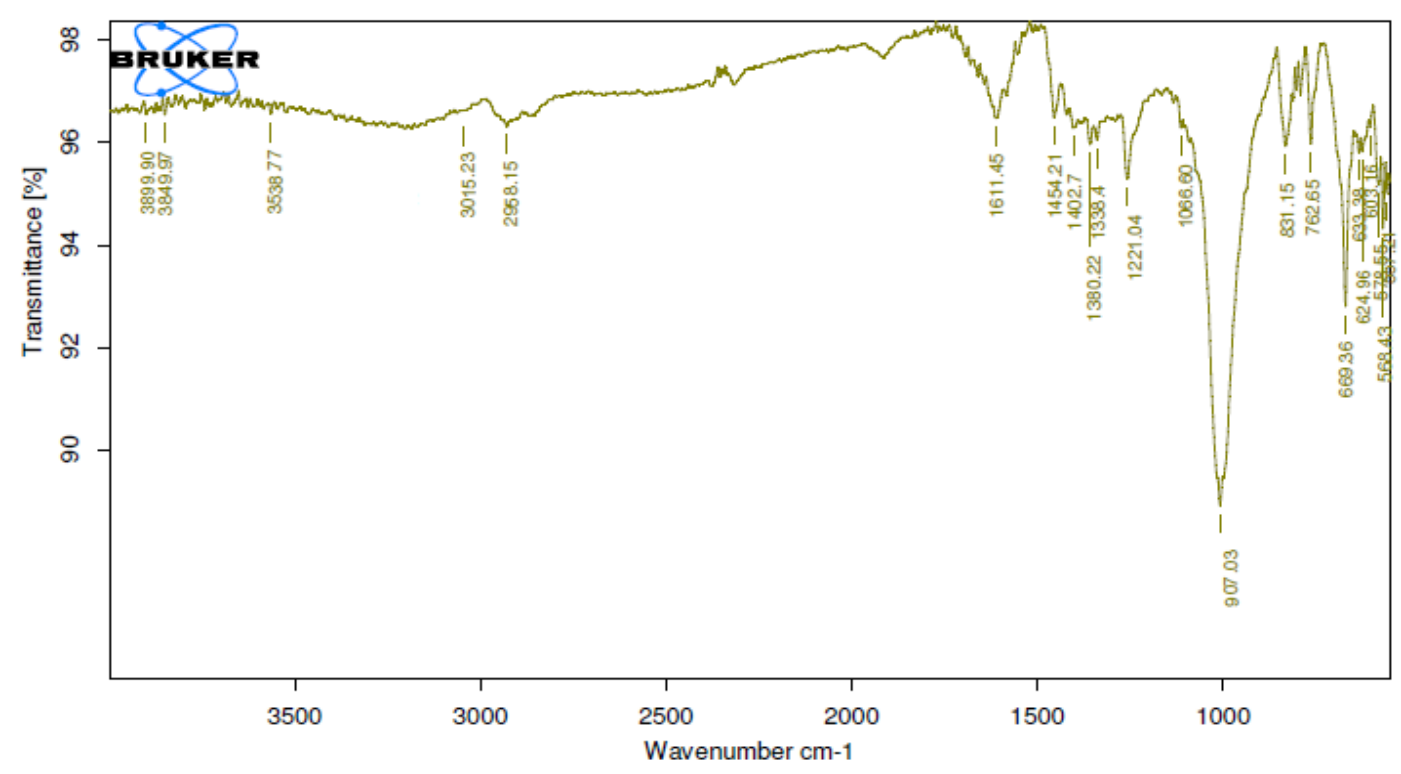

Figure 2 FTIR spectrum of optimized formulation

\subsection{Preparation of lovastatin ODTs}

The oral disintegrating thin films (ODTs) of lovastatin were designed by solvent casting method using Croscarmellose sodium (CCS) $(2,4$ and $6 \% \mathrm{w} / \mathrm{w})$, crospovidone (10 and $15 \% \mathrm{w} / \mathrm{w})$ as superdisintegrants, gelatin and polyvinyl alcohol (PVA) as a film forming base. Ten different formulation of lovastatin ODTs were prepared. 
Table 2 Evaluation of fast dissolving films of lovastatin

\begin{tabular}{cccc}
\hline $\begin{array}{c}\text { Formulation } \\
\text { Code }\end{array}$ & $\begin{array}{c}\text { Weight } \\
\text { (mg) }\end{array}$ & $\begin{array}{c}\text { Thickness } \\
\text { (mm) }\end{array}$ & $\begin{array}{c}\text { Folding } \\
\text { Endurance }\end{array}$ \\
\hline Fg & $63.92 \pm 0.12$ & $0.135+0.010$ & $272+1.674$ \\
F1 & $65.21 \pm 0.28$ & $0.140 \pm 0.005$ & $287 \pm 2.340$ \\
F2 & $65.90 \pm 0.31$ & $0.145 \pm 0.010$ & $289 \pm 2.640$ \\
F3 & $67.04 \pm 0.21$ & $0.150 \pm 0.010$ & $267 \pm 1.000$ \\
F4 & $66.84 \pm 0.38$ & $0.160 \pm 0.015$ & $271 \pm 1.730$ \\
F5 & $68.21 \pm 0.41$ & $0.165 \pm 0.005$ & $274 \pm 1.000$ \\
Fp & $51.02 \pm 0.24$ & $0.125+0.005$ & $265+1.253$ \\
F6 & $72.12 \pm 0.11$ & $0.170 \pm 0.010$ & $259 \pm 3.310$ \\
F7 & $49.91 \pm 0.32$ & $0.130 \pm 0.020$ & $266 \pm 2.000$ \\
F8 & $51.22 \pm 0.23$ & $0.130 \pm 0.015$ & $277 \pm 3.460$ \\
F9 & $52.18 \pm 0.41$ & $0.140 \pm 0.015$ & $260 \pm 1.000$ \\
F10 & $51.11 \pm 0.22$ & $0.145 \pm 0.015$ & $291 \pm 2.000$ \\
\hline
\end{tabular}

The prepared films were homogenous, colorless, smooth, and rough surface. The weight variation was found to be minimum as indicated by a small standard deviation of $\pm 0.33 \mathrm{mg}$. This observation also shows the uniform distribution of the ingredients in ODTs. The folding endurance of all batches observed between 259 to 291 . The thickness shows a narrow range of 0.125 to $0.170 \mathrm{~mm}$ further substantiating the above inference. The results showed uniformity in thickness.

Table 3 Evaluation of lovastatin ODTs

\begin{tabular}{cccc}
\hline $\begin{array}{c}\text { Formulation } \\
\text { Code }\end{array}$ & $\begin{array}{c}\text { Drug content } \\
\text { uniformity (\%) }\end{array}$ & $\begin{array}{c}\text { In vitro } \\
\text { disintegration time } \\
\text { (Sec) }\end{array}$ & Surface pH \\
\hline Fg & $95.54 \pm 0.253$ & $72.21 \pm 0.253$ & $6.67 \pm 0.154$ \\
Fp & $96.52 \pm 1.443$ & $70.43 \pm 0.165$ & $6.89 \pm 0.122$ \\
F1 & $96.66 \pm 0.925$ & $14.33 \pm 0.171$ & $6.76 \pm 0.153$ \\
F2 & $98.04 \pm 1.539$ & $9.10 \pm 0.435$ & $6.00 \pm 0.100$ \\
F3 & $97.33 \pm 0.369$ & $11.50 \pm 0.591$ & $6.46 \pm 0.115$ \\
F4 & $95.00 \pm 1.056$ & $18.76 \pm 0.151$ & $6.23 \pm 0.152$ \\
F5 & $97.66 \pm 1.396$ & $12.86 \pm 0.151$ & $6.66 \pm 0.152$ \\
F6 & $96.66 \pm 1.396$ & $14.10 \pm 0.479$ & $6.06 \pm 0.153$ \\
F7 & $97.66 \pm 1.545$ & $12.00 \pm 0.100$ & $6.83 \pm 0.057$ \\
F8 & $98.86 \pm 1.175$ & $7.23 \pm 0.151$ & $6.06 \pm 0.152$ \\
F9 & $97.24 \pm 1.001$ & $11.93 \pm 0.057$ & $6.33 \pm 0.152$ \\
F10 & $96.76 \pm 0.350$ & $15.41 \pm 0.076$ & $6.76 \pm 0.152$ \\
\hline
\end{tabular}

Surface $\mathrm{pH}$ of the film was measured in the range of 6-6.89 for all formulations (Table 3). Results show that surface $\mathrm{pH}$ of films are in the range of healthy human saliva, which is 6.3-7.3 [14]. Thus, the films are safe to be used in buccal cavity 
without any problem of irritation and thus patient acceptance will not be affected. Drug content of lovastatin ODTs was in the range of $96-98.86 \%$ implying uniform distribution of drug in the films. FDA recommends that, orally disintegrating tablets should be considered as solid oral preparations that disintegrate fast in mouth, with an in-vitro disintegration time of approximately less than or equal to 30 seconds, when the disintegration test conducted to the United States Pharmacopeia (USP) disintegration test method [15-17]. Lovastatin ODTs showed disintegration time of 9-18 sec and passes the limit for disintegration time.

Table 4 In vitro dissolution of lovastatin ODTs

\begin{tabular}{ccccccccccccc}
\hline & \multicolumn{10}{c}{} & \multicolumn{10}{c}{ \% Cumulative drug release (\% CDR) } \\
Time (min) & Fg & F1 & F2 & F3 & F4 & F5 & FP & F6 & F7 & F8 & F9 & F10 \\
\hline 0 & 0 & 0 & 0 & 0 & 0 & 0 & 0 & 0 & 0 & 0 & 0 & 0 \\
5 & 40.82 & 58.45 & 68.65 & 60.3 & 56.59 & 65.87 & 45.46 & 58.45 & 61.23 & 72.37 & 62.16 & 58.45 \\
10 & 43.6 & 64.94 & 74.22 & 64.94 & 62.16 & 73.29 & 48.24 & 63.09 & 69.58 & 77.93 & 71.44 & 64.94 \\
15 & 51.03 & 70.51 & 78.86 & 75.15 & 67.73 & 76.08 & 53.81 & 72.37 & 74.22 & 82.57 & 78.86 & 70.51 \\
20 & 56.59 & 77.01 & 84.43 & 82.57 & 74.22 & 81.64 & 59.38 & 80.72 & 78.86 & 89.07 & 84.43 & 77.93 \\
25 & 58.45 & 84.43 & 88.14 & 87.21 & 81.64 & 86.28 & 62.16 & 85.36 & 87.21 & 91.85 & 89.07 & 83.5 \\
30 & 61.23 & 91.85 & 98.35 & 94.63 & 89.07 & 95.56 & 64.02 & 92.78 & 94.63 & 99.27 & 96.49 & 91.85 \\
\hline
\end{tabular}

The results obtained in the in vitro drug release for the formulations were tabulated in table. In vitro dissolution study of all the batches showed $>90 \%$ drug dissolution in 30 min. The formulations F2, F5, F8 and F9 show drug release up to $>71 \%$ at the end of 10 min. Rapid drug dissolutions were observed in F87 which release 77.93 and 99.27 at the end of 10 and 30 min respectively as shown in Table 4.

\subsection{Drug release kinetics of lovastatin}

The experimental results of formulation F8 with zero order and the first order kinetics model, correlation coefficient are 0.226 and 0.838 . In-vitro drug release data of formulation (F8) obtained was fitted to kinetic models Zero order, first order, to know the pattern of drug release and mechanism of drug release from the ODTs. Formulation F8 followed first order with a good correlation coefficient ( $\mathrm{r} 2=0.838)$.

\subsection{Stability studies}

The selected formulation was evaluated for stability studies which was stored at $40{ }^{\circ} \mathrm{C}$ at $75 \% \mathrm{RH}$ tested for 3 month and was analyzed for their physical parameters, in vitro dispersion time and drug content at 1 month interval. The residual drug contents of formulations were found to be within the permissible limits which were estimated by measuring drug content uniformity. Lovastatin ODTs were found to be physically and chemically stable as they showed no significant change in terms of physical characteristics and drug content at a room temperature.

Table 5 Stability of F8 formulation of lovastatin ODTs

\begin{tabular}{cccc}
\hline $\begin{array}{c}\text { Stability period in } \\
\text { months }\end{array}$ & Physical appearance & $\begin{array}{c}\text { In-vitro dispersion time } \\
\text { (sec) }\end{array}$ & $\begin{array}{c}\text { Drug content } \\
\text { (\%) }\end{array}$ \\
\hline 1 & +++ (Excellent) & 7.33 & 98.40 \\
2 & +++ (Excellent) & 7.95 & 98.10 \\
3 & ++ (good) & 8.35 & 97.75 \\
\hline
\end{tabular}

Formulation $\mathrm{F} 8$ was stored at $40{ }^{\circ} \mathrm{C}$ and $75 \%$ relative humidity for stability study 


\section{Conclusion}

In the present study oral disintegrating drug delivery system of lovastatin was successfully developed in the form of oral disintegrating thin films. The optimized formulation of lovastatin ODTS (F8) was stable over a period of three months. These lovastatin ODTS offers a suitable and practical approach for faster disintegration and dissolution characteristics with increase bio-availability. For commercialization of optimized formulation of lovastatin ODTS (F8), bio availability studies should be performed in future.

\section{Compliance with ethical standards}

\section{Acknowledgments}

All authors are thankful to Department of Pharmaceutics, CMR College of Pharmacy, Kandlakoya (V), for providing library and laboratory facility for carrying out present research work.

\section{Disclosure of conflict of interest}

The authors have declared that no conflict of interest exists among them.

\section{References}

[1] Patel A and Prajapati D. (2010). Fast dissolving films (FDFs) as a newer venture in fast dissolving dosage forms. International Journal of Drug Development and Research, 2, 231-246.

[2] Kaur R and Bala R. (2012). Novel approach in oral fast dissolving drug delivery system -A review. American Journal of PharmTech Research, 2(1), 88-104.

[3] Bhyan B, Jangra S, Kaur M, Singh H. (2011).Orally fast dissolving films: innovations in formulation and technology. International Journal of Pharmaceutical Sciences Review and Research, 9(2), 9-15.

[4] Lakshmi PK, Sreekanth J and Sridharan Aishwarya. (2011). Formulation development of fast releasing oral thin films of levocetrizine dihydrochloride with Eudragit ${ }^{\circledR}$ Epo and optimization through Taguchi orthogonal experimental design. Asian Journal of Pharmaceutics, 5, 84-92.

[5] Jain JB, Bariya SD, Kapadia JR, Jani GK and Prajapati VD. (2015). Rapid mouth dissolving film: an innovative drug delivery system. World Journal of Pharmacy and Pharmaceutical Sciences, 4(5), 484-495.

[6] Seraman S, Rajendran A and Thangavelu V. (2010). Statistical optimization of anticholesterolemic drug lovastatin production by the red mold Monascus purpureus. Food and Bioproducts processing, 88, 266-276.

[7] Goswami S, Vidyarthi AS, Bhunia B and Mandal T. (2012). A review on lovastatin and its production. Journal of Biochemical Technology, 4(1), 581-587.

[8] Dennis VC, Britton ML, Sirmans SM, Letassy NA and Freeman DA. (1997). The use of alternate-day lovastatin in hypercholesterolemic men. Annals of Pharmacotherapy, 31(6), 708-712.

[9] Yellanki SK, Jagtap S and Masareddy R. (2011). Dissofilm: a novel approach for delivery of phenobarbital; design and characterization. Journal of Young Pharmacists, 3(3), 181-188.

[10] Joshi P, Patel H, Patel V and Panchal R. (2012). Formulation development and evaluation of mouth dissolving film of domperidone. Journal of pharmacy and bioallied sciences, 4(1), S108.

[11] Nafee NA, Boraie MA, Ismail FA and, Mortada LM. (2003). Design and characterization of mucoadhesive buccal patches containing cetylpyridinium chloride. Acta pharmaceutica (Zagreb, Croatia), 53(3), 199-212.

[12] Janßen EM, Schliephacke R, Breitenbach A and Breitkreutz J. (2013). Drug-printing by flexographic printing technology $-\mathrm{A}$ new manufacturing process for orodispersible films. International journal of pharmaceutics, 441(1-2), 818-825.

[13] Senthilkumar K and Vijaya C. (2015). Formulation development of mouth dissolving film of etoricoxib for pain management. Advances in Pharmaceutics, 2015.

[14] Aframian DJ, Davidowitz T and Benoliel R. (2006). The distribution of oral mucosal pH values in healthy saliva secretors. Oral diseases, 12(4), 420-423. 
[15] US Department of Health and Human Services, Food, and Drug Administration. (2008). Guidance for industry, orally disintegrating tablets. CDER-Data standards Manual. Chemistry, 1-3.

[16] Phasate, P, Chavan V, Tribhuvan N and Padamwar P. (2015). Mouth dissolving film: A novel approach to delivery of lisinopril. International Journal of Pharma Sciences and Research (IJPSR), Vol. 6(2), 398-405.

[17] Abay FB and Ugurlu T. (2015). Orally disintegrating tablets: a short review. Journal of Pharmaceutics \& Drug Development, 3(3), 303.

\section{How to cite this article}

Pagilla P, Vishnu P and Konde A. (2018). Formulation and evaluation of lovastatin oral disintegration thin films. GSC Biological and Pharmaceutical Sciences, 3(2), 35-42. 